\title{
Predictor Factors Influencing the Final Outcome and Treatment of Pediatric Patients with Acute Scrotum - Study For a Period of 10 Years
}

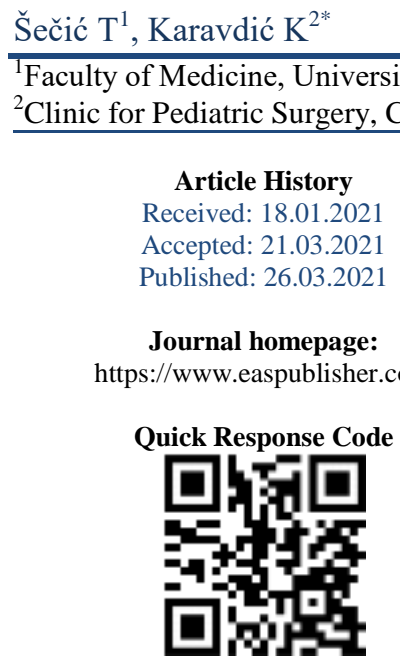


mainly deal with specific diseases that manifest as acute scrotum. Therefore, data on the overall incidence of acute scrotum in different population groups are incoherent. There are very few data on the incidence of acute scrotum within different pediatric age groups. It is estimated that $0.5 \%$ to $2.5 \%$ of all emergency room visits are related to the male genitourinary tract. The low specificity for acute scrotum in the above data can be attributed to both the broad etiology and the wide manifestation of the disease. The comparison of the acute scrotum with the acute abdomen is evident, due to the wide range of symptoms and clinical signs and their overlap and similar principles of treatment [1-4]. The scrotum is the outer protective sac that surrounds the testicles. It also has the role of temperature regulation with the aim of facilitating optimal spermatogenesis. The scrotum consists of the left and right halves that are intrascrotal separated by the septum. The position of the septum on external examination corresponds to the position of the Raphe scroti. The scrotal wall consists (from superficial to profuse): skin, superficial fascia, tunica dartos, external spermatic fascia, cremasteric fascia, and internal spermatic fascia. Inside the scrotum are the testicles, epididymis, and spermatic cord. All three structures have anatomical features and variations that are significant for the development and treatment of Scrotum accutum.

\section{MAterial AND Methods}

All selected patients were guided under the diagnosis of Scrotum accutum, and this is the main criterion for inclusion of patients in the study. This diagnosis included patients with Torsio testis, Torsio appendix testis, orchitis and / or epididymitis. Following the approval of the Institute for Scientific Research, 297 discharge letters from pediatric patients treated at the Clinic for Pediatric Surgery KCUS were retrospectively processed. All data were reviewed and collected once, electronically. Discharge documents include patients treated over a ten-year period (2009 to 2019).

Scientific research work is written on the principle of retrospective cohort study. Retrospectively based on the collected data (time period from 20092019) and cohort with regard to the classification of patients obtained by electronic examination of discharge documents of the Clinic with Pediatric Surgery KCUS. The cohort division of patients is primarily based on the type of treatment, with an additional categorical division based on the characteristics of the disease and the treatment of the patients (Chart-1). The study has the characteristics of observational, quantitative / analytical and applied study. Observational, because there is no influence and decision-making for exposure to a certain factor, but strict data collection in the current state (electronic review of discharge documents). Quantitative / analytical, with regard to the applied statistical methods for the purpose of presenting and processing data. The study contains the features of an applied study, in order to purposefully analyze the predictor factors related to Scrotum accutum, and that the results and discussion of the study be additional sources of information for the treatment of this disease.

\section{The Results}

From 89 patients treated conservatively: 59 Scrotum acc. (66.00\%), 18 Hydatida Morgagni torsion (20.00\%), 9 orchitis and epididimoorchitis (10.00\%), 3 Trauma (4.00\%) (Graph-1).

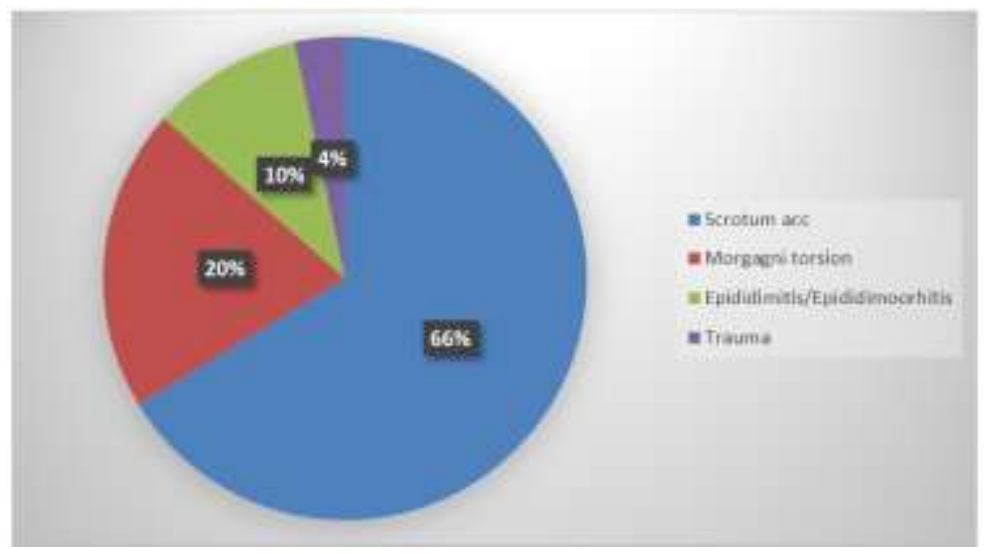

Graph-1: Conservatively treated patients

Of the 208 surgicaly treated patients: 55 testicular torsion $(26.00 \%), 141$ Morgagni torsion
(68.00\%), 11 orchitis and epididimoorchitis (5.00\%), 1 Trauma (1.00\%) (Graph-2). 


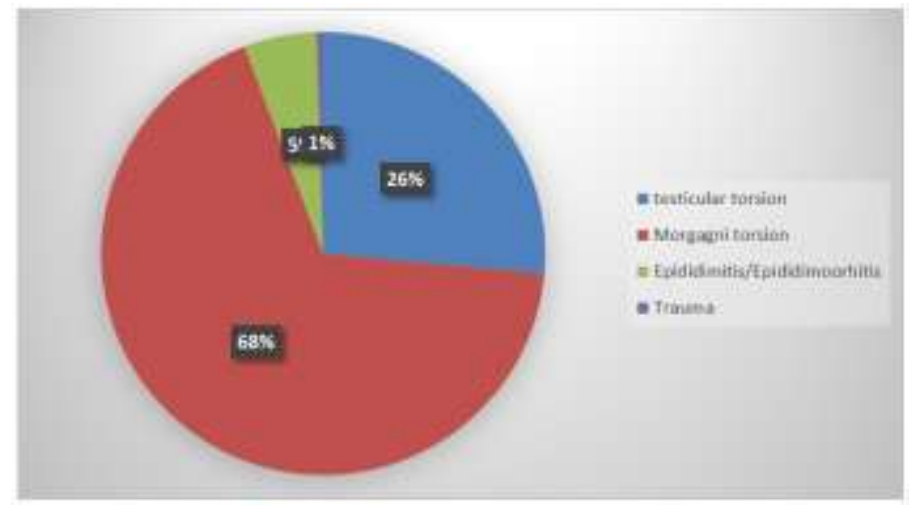

Graph-2: Surgicaly treated patients

Of the 55 patients with testicular torsion, in 35 cases the left testis was affected $(64.00 \%)$ and in 20 cases the right testis $(36.00 \%)$ (Graph-3).

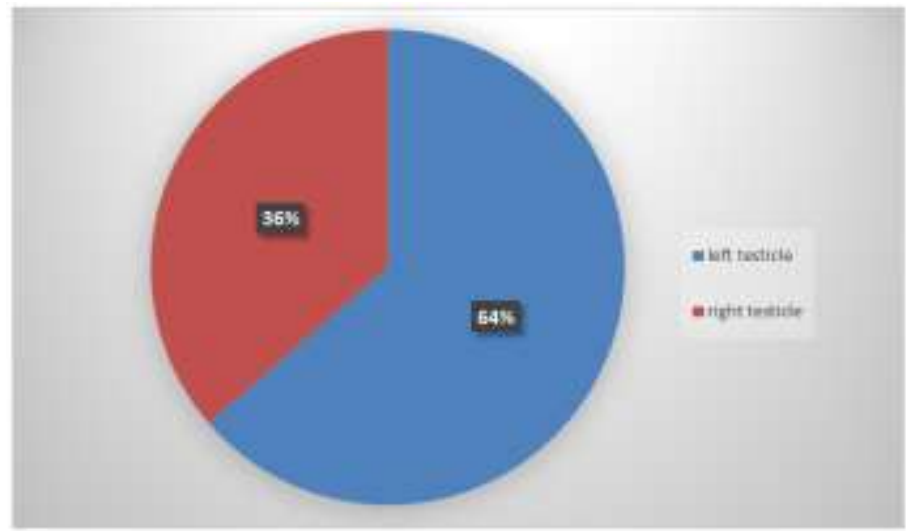

Graph-3: Testicular torsion

\section{Anamnestic data}

Table-1: Distribution by age of respondents

\begin{tabular}{|l|l|l|l|}
\hline Group /age & Conservative & Surgicaly & Total \\
\hline $0-8$ & $24(24.74 \%)$ & $73(75.25 \%)$ & 97 \\
\hline $9-14$ & $56(34.36 \%)$ & $107(65.64 \%)$ & 163 \\
\hline $15+$ & $9(24.32 \%)$ & $28(75.68 \%)$ & 37 \\
\hline Ukupno & $89(29.96 \%)$ & $208(70.04 \%)$ & 297 \\
\hline \multicolumn{4}{|c}{$X^{2}=3,3191 p=0.190255$} \\
\end{tabular}

There is no statistically significant difference between the groups of patients treated conservatively or surgically in relation to the age of the patients $(\mathrm{X} 2=$ $3.3191 \mathrm{p}=0.190255)$ Graph-4.

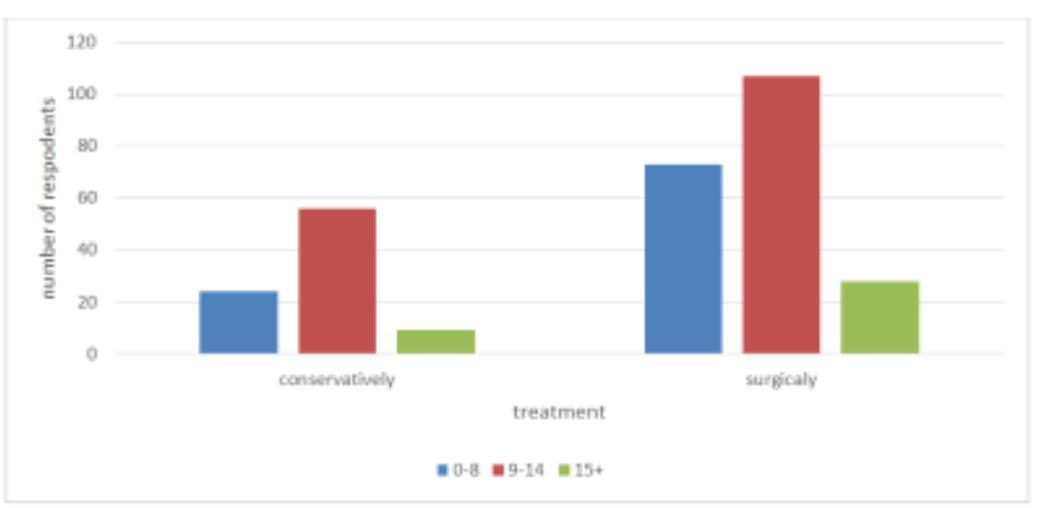

Graph-4: Distribution by age of respondents 
Table-2: Prepubertal age and testicular torsion.

\begin{tabular}{|l|l|l|l|}
\hline & No torsion & Testicular torsion & Total \\
\hline Prepubertal age & $109(82.58 \%)$ & $23(17.42 \%)$ & 132 \\
\hline Other age groups & $44(57.89 \%)$ & $32(42.11 \%)$ & 76 \\
\hline In total & 153 & 55 & 208 \\
\hline
\end{tabular}

$\mathrm{p}<0.05(\mathrm{x} 2=15.105)$, Fisher exact test shows one-sided and two-sided significance $(1$-sided $=0.000 ; 2$-sided $=0.000)$

In the category of patients without testicular torsion, out of 153 subjects, 109 subjects were in the age group $9-14$ years $(71.24 \%)$. In the category of patients with testicular torsion, out of 55 subjects, 23 were in the age group $9-14$ years $(41.82 \%)$. There is a statistically significant difference in prepubertal age (914 years) between patients without testicular torsion and patients with testicular torsion $(\mathrm{p}<0.05(\mathrm{p}<0.001)$, $\mathrm{p}=0.000)$.

Table-3: Prepubertal age and orchidectomy

\begin{tabular}{|l|l|l|l|}
\hline & Without Orchidectomy & Orchidectomy & Total \\
\hline Prepubertal age & $11(47.83 \%)$ & $12(52.17 \%)$ & 23 \\
\hline Other age groups & $15(46.88 \%)$ & $17(53.12 \%)$ & 32 \\
\hline In total & $26 \quad \mathrm{p}>0.05\left(\mathrm{x}^{2}=0.005\right)$ & 29 & 55 \\
\hline
\end{tabular}

In the category of patients without orchidectomy, out of 26 subjects, 11 subjects were in the age group $9-14$ years $(42.31 \%)$. In the group of patients with orchidectomy, out of 29 subjects, 12 subjects were in the age group of 9-14 years. There is no statistically significant difference between patients with orchidectomy and those without orchidectomy in prepubertal age $(p>0.05, p=0.944)$

Table-4: Neonatal / Infant age and testicular TORSION

\begin{tabular}{|l|l|l|l|}
\hline & No torsion & Testicular torsion & Total \\
\hline$<1$ year & $3(37.50 \%)$ & $5(62.50 \%)$ & 8 \\
\hline$>1$ year & $150(75.00 \%)$ & $50(25.00 \%)$ & 200 \\
\hline Ukupno & $153 \quad 0 \quad 55$ & 208 \\
\hline
\end{tabular}

In the category of patients without testicular torsion, out of 153 subjects, 3 subjects were younger than one year $(2.00 \%)$. In the category of patients with testicular torsion, out of 55 subjects, 5 subjects were younger than one year $(9.10 \%)$.
Inferential statistical analysis showed that there was a statistically significant difference in neonatal / infant age between patients with testicular torsion and patients without testicular torsion. ( $p<0.05$, $\mathrm{p}=0.0317)$

Table-5: Neonatal / Infant age and orchidectomy

\begin{tabular}{|l|l|l|l|}
\hline & Without Orchidectomy & Orchidectomy & Total \\
\hline$<$ 1 year & $1(20.00 \%)$ & $4(80.00 \%)$ & 5 \\
\hline$>$ 1 year & $25(50.00 \%)$ & $25(50.00 \%)$ & 50 \\
\hline Total & 26 & 29 & 55 \\
\hline \multicolumn{2}{|c|}{$\mathrm{p}>0.05\left(\mathrm{x}^{2}=1.6412\right)$} \\
\hline
\end{tabular}

In the category of patients with testicular torsion, out of 55 subjects, 5 subjects were younger than one year $(9.10 \%)$. Out of that, 1 patient is in the category "Without Orchidectomy" and 4 patients are in the category "Orchidectomy". Differential statistical analysis of the data showed that there was no statistically significant difference in neonatal / infant age between patients with orchidectomy and those without orchidectomy $(p>0.05, p=0.200)$.

Table-6: Duration of symptoms

\begin{tabular}{|l|l|l|l|l|}
\hline Category (number of respondents) & Raspon(Min-Max) & Mean & Median & p value \\
\hline Conservatively(89) & $10(0-10)$ & 2.53 & 2.00 & $\mathrm{p}>0.05(\mathrm{p}=0.337)$ \\
\hline Surgicaly(208) & $30(0-30)$ & 2.65 & 2.00 & \\
\hline No torsion (153) & $30(0-30)$ & 3.06 & 2.00 & $\mathrm{p}<0.05(\mathrm{p}=0.000)$ \\
\hline Testical torsion(55) & $14(0-14)$ & 1.55 & 1.00 & \\
\hline
\end{tabular}


There was no statistically significant difference in the duration of symptoms between surgically and conservatively treated patients $(\mathrm{p}>0.05, \mathrm{p}=0.337)$.
There is a statistically significant difference in the duration of symptoms between patients without testicular torsion and patients with testicular torsion. ( $\mathrm{p}$ $<0.05 / \mathrm{p}<0.0001)$.

Table-7: Duration of symptoms in orchidectomy

\begin{tabular}{|l|l|l|l|}
\hline & Without Orchidectomy & Orchidectomy & Total \\
\hline$<6$ hours & $19(86.36 \%)$ & $3(13.64 \%)$ & 22 \\
\hline$>6$ hours & $7(21.21 \%)$ & $26(78.79 \%)$ & 33 \\
\hline Ukupno & 26 & 29 & 55 \\
\hline \multicolumn{4}{|c|}{$p<0.05(\mathrm{p}=0.000)$}
\end{tabular}

There is a statistically significant difference in the duration of symptoms between patients without orchidectomy and patients with orchidectomy. ( $\mathrm{p}<0.05$ / $\mathrm{p}<0.0001)$

Table-8: General symptoms

\begin{tabular}{|c|c|}
\hline General symptoms & Total \\
\hline Nausea & 7 \\
\hline Vomiting & 16 \\
\hline Absence of stool & 1 \\
\hline Food refusal & 2 \\
\hline Fever & 7 \\
\hline Dysuric problems & 5 \\
\hline Difficulty walking & 7 \\
\hline Itching & 1 \\
\hline
\end{tabular}

Out of a total of 297 respondents, only 46 showed general symptoms. 16 subjects $(5.39 \%)$ had vomiting, 7 subjects $(2.46 \%)$ had nausea, fever and difficulty walking, 5 (1.68\%) subjects had dysuric problems, $2(0.67 \%)$ subjects refused food and 1
$0.34 \%$ ) the subject had no stools and no itching. Given the low frequency of these descriptive data, it is not appropriate to perform a more detailed statistical analysis of the data related to general symptoms.

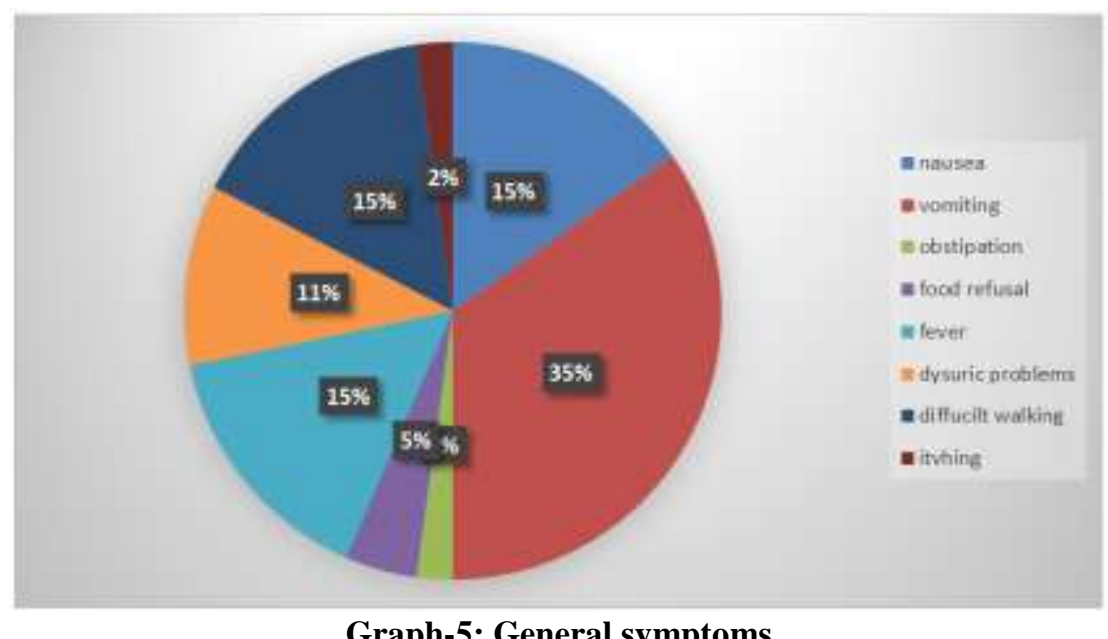

Graph-5: General symptoms

Conservatively treated patients / Operatively treated patients 
Table-9: Clinical signs

\begin{tabular}{|l|l|l|l|l|}
\hline & Conservative & Surgical & Total & p value \\
\hline Pain present / number of subjects & $89 / 89$ & $208 / 208$ & $297 / 297$ & \\
\hline Proximal testicular pain & $30(22.06 \%)$ & $106(77.94 \%)$ & 136 & $<0.05$ \\
\hline Inguinal pain & $1(5.88 \%)$ & $16(94.12 \%)$ & 17 & $<0.05$ \\
\hline Abdominal pains & $2(15.38 \%)$ & $11(84.62 \%)$ & 13 & $>0.05$ \\
\hline Leg pain & 2 & 0 & 2 & $/$ \\
\hline Scrotal hyperemia & $31(16.58 \%)$ & $156(83.42 \%)$ & 187 & $<0.05$ \\
\hline Scrotal edema & $24(13.64 \%)$ & $152(86.36 \%)$ & 176 & $<0.05$ \\
\hline Abnormal testicular position & $3(10.34 \%)$ & $26(89.66 \%)$ & 29 & $<0.05$ \\
\hline Pathological changes of the testes & $17(37.78 \%)$ & $37(82.22 \%)$ & 45 & $>0.05$ \\
\hline Pathological changes of the epididymis & $10(50.00 \%)$ & $10(50.00 \%)$ & 20 & $<0.05$ \\
\hline Pain and other funicular changes & $2(25.00 \%)$ & $6(75.00 \%)$ & 8 & $>0.05$ \\
\hline Cremasteric reflex & 0 & 2 & 2 & $/$ \\
\hline Hydrocele present & $7(6.86 \%)$ & $95(93.14 \%)$ & 102 & $<0.05$ \\
\hline Palpable intrascrotal formation & $7(35.00 \%)$ & $13(65.00 \%)$ & 20 & $>0.05$ \\
\hline Prehn's sign & $2(50.00 \%)$ & $2(50.00 \%)$ & 4 & $>0.05$ \\
\hline
\end{tabular}

Predictor factors "Proximal testicular pain", "Inguinal pain", "Scrotum hyperemia", "Scrotum edema", "Abnormal testicular position", "Pathological changes of the epididymis" and "Present hydrocele" show statistically significant differences between conservatively and surgically treated patients.

Table-10: Diagnostic methods

\begin{tabular}{|l|l|l|l|l|}
\hline & Conservative & Surgical & Total & p value \\
\hline Ultrasound and Color Doppler / number of patients & $88 / 89$ & $191 / 208$ & $279 / 297$ & \\
\hline Testicular hypovascularity & $1(4.00 \%)$ & $24(96.00 \%)$ & 25 & $<0.05$ \\
\hline Testicular hypervascularity & $4(44.44 \%)$ & $5(55.56 \%)$ & 9 & $>0.05$ \\
\hline Testicular avascularity & 0 & $34(100 \%)$ & 34 & $<0.05$ \\
\hline Hypoechogenicity of the testis & $1(6.25 \%)$ & $15(93.75 \%)$ & 16 & $<0.05$ \\
\hline Testicular heteroechogenicity & 0 & $21(100 \%)$ & 21 & $<0.05$ \\
\hline Other pathological changes of the testis & $17(26.98 \%)$ & $46(73.12 \%)$ & 63 & $>0.05$ \\
\hline Pathological changes of the epididymis & $45(38.14 \%)$ & $73(61.86 \%)$ & 118 & $<0.05$ \\
\hline Verified testicular adnexa torsion & $36(24.00 \%)$ & $114(76.00 \%)$ & 150 & $<0.05$ \\
\hline Verified presence of hydrocele & $21(16.03 \%)$ & $110(83.97 \%)$ & 131 & $<0.05$ \\
\hline
\end{tabular}

Predictor factors exhibit statistically significant differences between conservatively and surgically treated patients.
Surgically treated patients without testicular torsion / Surgically treated patients with testicular torsion.

In the group of clinical signs; "Inguinal pain", "Scrotal hyperemia", "Scrotal edema","

Table-11: Clinical signs

\begin{tabular}{|l|l|l|l|l|}
\hline Pain / number of patients present & $153 / 153$ & $55 / 55$ & $208 / 208$ & \\
\hline Proximal pain & $103(97.17 \%)$ & $3(2.83 \%)$ & 106 & $\mathrm{p}<0,05$ \\
\hline Inguinal pain & $9(56.25 \%)$ & $7(43.75 \%)$ & 16 & $\mathrm{p}>0.05$ \\
\hline Abdominal pains & $2(18.18 \%)$ & $9(81.82 \%)$ & 11 & $\mathrm{p}<0.05(\mathrm{p}<0.0001)$ \\
\hline Leg pain & 0 & 0 & 0 & $/$ \\
\hline Scrotal hyperemia & $120(76.92 \%)$ & $36(23.08 \%)$ & 156 & $\mathrm{p}>0.05(\mathrm{p}=0.056)$ \\
\hline Scrotal edema & $113(74.34 \%)$ & $39(25.66 \%)$ & 152 & $\mathrm{p}>0.05$ \\
\hline Abnormal testicular position & 0 & $26(100 \%)$ & 26 & $\mathrm{p}<0.00001$ \\
\hline Pathological changes of the testes & $15(40.54 \%)$ & $22(59.46 \%)$ & 37 & $\mathrm{p}<0.00001$ \\
\hline Pathological changes of the epididymis & $7(70.00 \%)$ & $3(30.00 \%)$ & 10 & $\mathrm{p}>0.05$ \\
\hline Pain and other funicular changes & $3(50.00 \%)$ & $3(50.00 \%)$ & 6 & $\mathrm{p}>0.05$ \\
\hline Cremasteric reflex & 0 & $2(100 \%)$ & 2 & $/$ \\
\hline Hydrocele present & $69(72.63 \%)$ & $26(27.37 \%)$ & 95 & $\mathrm{p}>0.05$ \\
\hline Palpable intrascrotal formation & $13(100 \%)$ & 0 & 13 & $\mathrm{p}>0.05(\mathrm{p}=0.056)$ \\
\hline Prehn's sign & $1(50.00 \%)$ & $1(50.00 \%)$ & 2 & $\mathrm{p}>0.05$ \\
\hline
\end{tabular}


Predictor factors; "Proximal pain", "Abdominal pain", "Abnormal testicular position" (Mann Whitney U test) and "Pathological testicular changes" show statistically significant differences between patients without testicular torsion and patients with testicular torsion.

Table-12: Diagnostic methods

\begin{tabular}{|l|l|l|l|l|}
\hline & No testicular torsion & Esticular torsion & Total & p value \\
\hline $\begin{array}{l}\text { Diagnostic methods: UZ and Color Doppler } \\
\text { / number of subjects }\end{array}$ & $138 / 153$ & $53 / 55$ & $191 / 208$ & \\
\hline Testicular hypovascularity & $6(25.00 \%)$ & $18(75.00 \%)$ & 24 & $\mathrm{p}<0.00001$ \\
\hline Testicular hypervascularity & $5(100 \%)$ & 0 & 5 & $\mathrm{p}>0.05$ \\
\hline Testicular avascularity & $1(2.94 \%)$ & $33(97.06 \%)$ & 34 & $\mathrm{p}<0.00001$ \\
\hline Hypoechogenicity of the testis & $1(6.57 \%)$ & $14(93.33 \%)$ & 15 & $\mathrm{p}<0.00001$ \\
\hline Testicular heterogeneity & 0 & $21(100 \%)$ & 21 & $\mathrm{p}<0.00001$ \\
\hline Other pathological changes of the testis & $27(58.70 \%)$ & $19(41.30 \%)$ & 46 & $\mathrm{p}<0.05$ \\
\hline Pathological changes of the epididymis & $66(90.41 \%)$ & $7(9.59 \%)$ & 73 & $\mathrm{p}<0.00001$ \\
\hline Verified testicular adnexa torsion & $113(99.12 \%)$ & $1(0.88 \%)$ & 114 & $\mathrm{p}<0.0001$ \\
\hline Hydrocele present & $83(75.45 \%)$ & $27(24.55 \%)$ & 110 & $\mathrm{p}>0.05$ \\
\hline
\end{tabular}

Predictor factors; "Testicular hypovascularity", "Testicular avascularity", "Testicular hypoechoicity", "Testicular heteroechogenicity", "Epididymal pathological changes" and "Verified testicular adnexa torsion" show statistically significant differences between patients without testicular torsion and patients with testicular torsion.

Table-13: Laboratory analysis

\begin{tabular}{|l|l|l|l|l|}
\hline & No testicular torsion & Testicular torsion & Total & P value \\
\hline Laboratory / number of respondents & $109 / 153$ & $49 / 55$ & $158 / 208$ & \\
\hline Leukocytosis & $23(46.00 \%)$ & $27(54.00 \%)$ & 50 & $\mathrm{p}<0.05$ \\
\hline Elevated CRP & $12(30.00 \%)$ & $28(70.00 \%)$ & 40 & $\mathrm{p}<0.00001$ \\
\hline Urine analysis / number of subjects & $11 / 153$ & $2 / 55$ & $13 / 208$ & \\
\hline
\end{tabular}

In the group of laboratory analyzes; "Leukocytosis" and "Elevated CRP" show statistically significant differences between patients without testicular torsion and patients with testicular torsion.
Surgically treated patients without orchidectomy / Surgically treated patients with orchidectomy

Table-14: Diagnostic procedures

\begin{tabular}{|l|l|l|l|l|}
\hline & No orchidectomy & Orchidectomy & total & p value \\
\hline Diagnostic procedures / total number of subjects & $24 / 26$ & $29 / 29$ & $53 / 55$ & \\
\hline Testicular hypovascularity & $17(94.44 \%)$ & $1(5.56 \%)$ & 18 & $\mathrm{p}<0.00001$ \\
\hline Testicular hypervascularity & 0 & 0 & 0 & $/$ \\
\hline Testicular avascularity & $5(15.15 \%)$ & $28(84.85 \%)$ & 33 & $\mathrm{p}<0.00001$ \\
\hline Hypoechogenicity of the testis & $12(85.71 \%)$ & $2(14.29 \%)$ & 14 & $\mathrm{p}<0.05$ \\
\hline Testicular heteroechogenicity & $1(4.76 \%)$ & $20(95.24 \%)$ & 21 & $\mathrm{p}<0.00001$ \\
\hline Other pathological changes of the testis & $8(42.11 \%)$ & $11(57.89 \%)$ & 19 & $\mathrm{p}>0.05$ \\
\hline Pathological changes of the epididymis & $4(57.14 \%)$ & $3(42.86 \%)$ & 7 & $\mathrm{p}>0.05$ \\
\hline Verified torsional adnexa torsion & 0 & $1(100 \%)$ & 1 & $/$ \\
\hline Presence of hydrocele & $16(59.26 \%)$ & $11(40.74 \%)$ & 27 & $\mathrm{p}>0.05$ \\
\hline
\end{tabular}

Predictor factors "Testicular hypovascularity", "Testicular avascularity", "Testicular hypoechogenicity", "Testicular heteroechogenicity" show statistically significant differences between patients without orchidectomy and patients with orchidectomy.

Table-15: Laboratory analysis

\begin{tabular}{|l|l|l|l|l|}
\hline & No orchidectomy & Orchidectomy & Total & p value \\
\hline Laboratory / total number of respondents & $24 / 26$ & $25 / 29$ & $49 / 55$ & \\
\hline Leukocytosis & $14(51.85 \%)$ & $13(48.15 \%)$ & 27 & $\mathrm{p}>0.05$ \\
\hline Elevated CRP & $6(21.43 \%)$ & $22(78.57 \%)$ & 28 & $\mathrm{p}<0.00001$ \\
\hline Urine analysis / total number of subjects & $0 / 26$ & $2 / 29$ & $2 / 55$ & \\
\hline
\end{tabular}


The predictor factor "Elevated CRP" shows a statistically significant difference between patients with orchidectomy and patients without orchidectomy.

Table-16: Length of hospitalization

\begin{tabular}{|l|l|l|l|l|}
\hline & Range(Min-Max) & Median & Mean & p value \\
\hline Conservative & $19(1-20)$ & 4.00 & 5.56 & $\mathrm{p}<0.05(0.0001)$ \\
\hline Surgical & $20(2-20)$ & 6.00 & 6.62 & \\
\hline No Torsion & $16(2-18)$ & 6.00 & 6.56 & $\mathrm{p}>0.05$ \\
\hline Torsion & $19(3-22)$ & 6.00 & 6.76 & \\
\hline Without Orchidectomy & $19(3-22)$ & 6.00 & 7.19 & $\mathrm{p}>0.05$ \\
\hline Orchidectomy & $9(3-12)$ & 5.00 & 6.17 & \\
\hline
\end{tabular}

There is a statistically significant difference in the duration of hospitalization between surgically and conservatively treated patients $(\mathrm{p}<0.05 / \mathrm{p}<0.00001)$.

Table-17: Orchidectomy and torsion side

\begin{tabular}{|l|l|l|l|}
\hline & No orchidectomy & Orhidektomija & Total \\
\hline Left testicle & $16(45.71 \%)$ & $19(54.29 \%)$ & 35 \\
\hline Right testicle & $10(50.00 \%)$ & $10(50.00 \%)$ & 20 \\
\hline In total & 26 & 29 & 55 \\
\hline \multicolumn{4}{|l}{$\mathrm{x}^{2}=0.0938, \mathrm{p}=0.759, \mathrm{p}>0.05$} \\
\end{tabular}

There is no statistically significant difference between patients with left or right testicular torsion compared to orchidectomy.

\section{DISCUSSION}

Acute scrotum is an urgent medical condition, requiring conservative or surgical treatment. It is characterized by acute pain, redness and enlargement, and includes various diseases in its etiology. Testicular torsion is the most important diagnostic modality, while torsion of intrascrotal adnexa with epididymitis / epididymoorchitis occupy a secondary position in the order of urgency of timely diagnosis. Predictor factors influencing a positive outcome and the appropriate type of treatment are one of the key research topics in the field of acute scrotum.

This study included 297 patients. Subjects of this study were divided into 6 categories based on outcome and treatment. Out of 6 categories, 3 cohorts were created for statistical analysis of data. By Category 2 treatment, Conservatively and Operatively treated patients, forming a cohort of Conservatively / Operatively treated patients. According to the outcome of 4 categories: No testicular torsion, testicular torsion, no orchidectomy, orchidectomy. 2 cohorts were created in these categories: No Testicular Torsion / Testicular Torsion, No Orchidectomy / Orchidectomy.

Predictor factors were selected and divided based on personal medical knowledge and relevant medical research papers / medical literature. Anamnestic data are the first that a medical professional comes into contact with, followed by an extensive clinical examination in order to endow the relevant clinical signs. Diagnostic imaging procedures, ultrasound and $\mathrm{CD}$, have acquired the gold standard characteristic in recent years. Laboratory findings provide relevant data, and their contribution should not be neglected.

Inferential statistical analysis showed that there was no significant difference between surgically and conservatively treated patients when it comes to the age of the subjects. 3 age groups were established: 0-8, 9-14, 15+ years, based on the study of Cost et al., [5] Age group 9-14 years, was presented as prepubertal and was used in the study of the cohort "No Testicular Torsion / Testicular Torsion" and "Without Orchidectomy / Orchidectomy". Prepubertal age, as a predictor factor, is also associated with the category of respondents "Without Testicular Torsion" and "Testicular Torsion" (Table 2). However, no significant difference was obtained in the "No Orchidectomy / Orchidectomy" cohort (Table-3). Although the study by Goetz et al., associates the prepubertal age group with a higher incidence of orchidectomy than the postpubertal one [6]. Observing the frequencies of prepubertal age and testicular torsion, in both categories it is represented in a high percentage in relation to the total number of respondents in each category. Prepubertal age is reported as one of the two peaks in the incidence of testicular torsion [7], but in this study it shows a twoway direction of impact. The second peak of testicular torsion is neonatal / infant age, and the predictor role of this variable in testicular torsion was confirmed in this study. In relation to orchidectomy, a 6-hour model of testicular survival was taken, and the relevant influence of symptom duration and testicular survival was shown. The study by Nadwnani et al., shows that the risk of orchidectomy is significantly associated with the duration of symptoms and that in groups with a duration of symptoms over 6 hours, the testicular survival rate is 
lower. The study by Mellick et al., indicates that testicular survival is significant after a 6-8 hour period $[8,9]$. The study did not take into account the so-called "Door-to-detorsion time", the period from admission to treatment. Gold et al. analyzed this factor and concluded that every 10 minutes of treatment delay in clinical conditions increases the risk of testicular loss by $4.8 \%$. (10) When comparing the age and duration of symptoms in relation to testicular torsion and orchidectomy, studies more often cite the duration of symptoms as a more significant predictor factor. Our results show a similar interpretation although age is still important as a predictor factor [11-14]. General symptoms are one of the least investigated groups of predictor factors in this study, primarily due to the low frequency of occurrence within all categories of subjects. Vomiting has the highest frequency (5.39\%), followed by nausea, fever and difficulty walking $(2.46 \%)$.

With the formulation of the TWIST scoring system in 2013, a study by Barbosa et al., Nausea / vomiting play a significant predictor role in evaluating potential cases of operative patients with testicular torsion [15].

In this study, this correlation was not found due to the lack of an adequate number of subjects with nausea / vomiting in any category. However, nausea and vomiting contain clinical value, specific to testicular torsion $[16,17]$.

Difficulty walking is a general symptom that occurred in extremely swollen scrotums, and did not show a difference in frequency between the categories of subjects. Fever indicates inflammatory processes and is associated with patients with epididymitis / epididymoarrhythmia. In the category of conservative patients EP / EPO are present in $10.00 \%$ of cases, and in the category of surgical patients in $5.00 \%$ of cases. In conservative patients, fever was noted 1 time and in surgical patients 6 times, showing that there is an association between fever and EP / EPO, but it is not significant to fully support this statement [14]. Abdominal pain has a high significant result in our study. Pogorelic et al., state $25.30 \%$ of the frequency of inguinal pain in the group of patients with testicular torsion, with the mention of abdominal pain as a relevant predictor factor which may be the only manifestation in the case of testicular torsion [12]. Abnormal testicular position and pathological testicular changes are one of the most important fields of interest in the evaluation of predictor factors. In addition to the cremasteric reflex, nausea / vomiting form the basis of the aforementioned Barbosa et al. a study that defined the TWIST categorization for testicular torsion. Abnormal testicular position is manifested within surgical patients as: 15 high and 17 transversely positioned testicles. Initial study, Barbosa et al. (those other studies) cite a highly positioned testis, other studies also cite a transverse position as indicative of testicular torsion [15-17]. Data analysis found low frequencies for two very specific signs, the Cremasteric Reflex and the Prehn sign. The absent cremasteric reflex is characterized by a high positive predictive value in terms of testicular torsion [18-21].

In our study, it was mentioned only 2 times, in surgical patients and consequently in patients with testicular torsion. With such a low frequency and disabled inferential statistical analysis, it is not possible to check the validity of the absent cremasteric reflex in the area of the acute scrotum.

The same problem applies to Prehn's sign. It has been noted only 4 times, 2 in conservative patients and 2 in surgical patients. Prehn's sign has a predictor value in testicular torsion and epididymitis [22]. However, in this study, the validity of the Prehn mark cannot be fully examined

Studies indicate an association of hypovascular / avascular with testicular torsion. In fact, they are presented as the most significant sign of testicular torsion. This area also includes the mention of vascular changes of the funicular (noted in our study under "Testicular hypervascularity"), presented as a whirlpool sign or pseudomass (funicular-epididymal) which has an even more significant predictor value than the whirlpool sign [23-25].

This study supported the predictor value of hypovascularity / avascularity in the evaluation of acute scrotum and the diagnosis of testicular torsion. Specifically, the association of hypovascularity with orchidectomy and avascularity with orchidectomy is indicated. Vascular phenomena of the spermatic cord, related to testicular torsion, and testicular hypervascularity in some other conditions (inflammatory diseases, TM) are not supported by this study [26].

However, it should be noted the possibility of preserved flow in the case of testicular torsion, and the confusing radiological findings obtained by analysis of these patients. Bandakar et al., report false-negative and false-positive findings in patients with TT or EP / EPO, making timely diagnosis and treatment difficult [24].

The second segment includes parenchymal changes in testicular structure. Testicular hypoechogenicity is associated with hypovascularity and surgical procedure without orchidectomy. Testicular heteroechogenicity is associated with avascularity and orchidectomy surgery. Cokkinos et al., study, describes hypoechogenicity / hypovascularization as "new / current" testicular torsion and thus a higher incidence of rescuing the affected testis. On the other hand, he describes heteroechogenicity as "past / complete torsion" that has 
caused irreparable damage to testicular tissue [27-30]. studies support the role of leukocytosis and elevated CRP as signs of the inflammatory process. Although, inflammatory parameters have no specific prognostic significance for susceptible patients in the acute scrotum domain $[31,32]$. The role of prognostic factors in the evaluation of acute scrotum shows certain differences, and absolute certainty in the validity of individual factors is not entirely possible. Anamnestic data, General symptoms, Clinical signs, Diagnostic procedures, laboratory analysis are the most important groups of prognostic factors whose role, use and validity are examined. The most numerous prognostic factors are in the group of clinical signs, although only 12 of them $(36.36 \%)$ showed $p$ values of statistical significance. On the other hand, diagnostic procedures, presented through 25 factors, have the largest share of statistical significance by number (18/25) and percentage $(72.00 \%)$. Laboratory analysis also has a high percentage of significant values, but only 6 overall prognostic factors. General symptoms, although often mentioned as influential prognostic factors, did not result in significant results throughout our study. Anamnestic data were presented with 5/14 significant values, $35.71 \%$.

The importance of diagnostic procedures as the leading group of prognostic factors is evident. The TWIST scoring system, introduced by Barbosa et al., [15], enabled the use of clinical signs as the last link in the decision to treat a patient with acute scrotum. Primarily this system refers to testicular torsion. Its role, as a top diagnostic modality, has been shown through certain scientific research papers [33].

Although, diagnostic imaging procedures, ultrasound and CD possess $85-100 \%$ sensitivity and 75$100 \%$ specificity for testicular torsion. Through this role study, the role of ultrasound and CD in the recognition of tortured intrascrotal adnexa (mostly TM) was presented. EP / EPO shows certain characteristics that $\mathrm{UZ}$ and $\mathrm{CD}$ note, and enable the doctor to make adequate diagnoses. Ultrasound and $\mathrm{CD}$ continue to play a leading role in the evaluation of acute scrotum, and their availability in tertiary clinical conditions is essential [34, 35].

The TWIST scoring system has enabled the rapid treatment of patients who appear to be borderline patients. This system provides a justified operational approach, and in cases of impossibility of ultrasound and $\mathrm{CD}$ analysis is the best diagnostic direction.

If the physician is in doubt, with no ultrasound and $\mathrm{CD}$ performed, and clinical signs suggest testicular torsion, ultrasound and $\mathrm{CD}$ should not delay surgical treatment [36].

\section{Conclusions}

- Prognostic factors significant for patients with testicular torsion are: Prepubertal and Neonatal / Infant age, Duration of symptoms, Abdominal age, Abnormal testicular position, Pathological changes of testicles, Vascular and Parenchymal changes of testicular parenchyma (Diagnostic methods), Other pathological .methods), Leukocytosis, Elevated CRP

- Prognostic factors that indicate the outcome of orchidectomy are Testicular avascularity, Testicular heteroechogenicity, Elevated CRP. diagnostic methods UZ and CD, take a leading role in the prognosis of outcomes.

- The TWIST scoring system showed a statistical impact in 3 of the 5 factors listed in our study. Nausea // Vomiting and Absent creamy reflex due to lack of data are not shown as relevant factors.

- Diagnostic methods (US and CD) have a higher prognostic value than clinical signs.

- The validity of laboratory findings in the evaluation of acute scrotum is present, but not crucial for timely diagnoses, correct treatment and a positive outcome.

\section{REFERENCES}

1. Keays, M., \& Rosenberg, H. (2019). Testicular torsion. Canadian Medical Association Journal. 191(28):E792-E792.

2. Nallikuzhy, T. J., Rajasekhar, S. S. S. N., Malik, S., Tamgire, D. W., Johnson, P., \& Aravindhan, K. (2018). Variations of the testicular artery and vein: A meta-analysis with proposed classification. Clinical Anatomy, 31(6), 854-869.

3. Jefferies, M. T., Cox, A. C., Gupta, A., \& Proctor, A. (2015). The management of acute testicular pain in children and adolescents. Bmj, 350 .

4. Kim, J. S., Shin, Y. S., \& Park, J. K. (2018). Clinical features of acute scrotum in childhood and adolescence: Based on 17 years experiences in primary care clinic. The American journal of emergency medicine, 36(7), 1302-1303.

5. Cost, N. G., Bush, N. C., Barber, T. D., Huang, R., \& Baker, L. A. (2011). Pediatric testicular torsion: demographics of national orchiopexy versus orchiectomy rates. The Journal of urology, 185(6S), 2459-2463.

6. Goetz, J., Roewe, R., Doolittle, J., Roth, E., Groth, T., Mesrobian, H. G., ... \& Kryger, J. (2019). A comparison of clinical outcomes of acute testicular torsion between prepubertal and postpubertal males. Journal of pediatric urology, 15(6), 610616.

7. Yang, C., Song, B., Tan, J., Liu, X., \& Wei, G. H. (2011). Testicular torsion in children: a 20-year retrospective study in a single institution. The Scientific World Journal, 11, 362-368. 
8. Nandwani, G. M., Anwar, A., Singh, R., Stewart, A. B., Forster, J. A., \& Addla, S. K. (2020). Assessment of age and duration of symptoms on outcomes of emergency scrotal exploration for acute scrotal pain. Journal of the College of Physicians and Surgeons Pakistan, 30(2), 201204.

9. Meliick, L. B., Sinex, J. E., Gibson, R. W., \& Mears, K. (2017). A systematic review of testicle survival time following a torsion event. Pediatric Emergency Care.

10. Gold, D. D., Lorber, A., Levine, H., Rosenberg, S., Duvdevani, M., Landau, E. H., ... \& Hidas, G. (2019). Door to detorsion time determines testicular survival. Urology, 133, 211-215.

11. Ramachandra, P., Palazzi, K. L., Holmes, N. M., \& Marietti, S. (2015). Factors influencing rate of testicular salvage in acute testicular torsion at a tertiary pediatric center. Western Journal of Emergency Medicine, 16(1), 190-194.

12. Pogorelić, Z., Mustapić, K., Jukić, M., Todorić, J., Mrklić, I., Mešštrović, J., ... \& Furlan, D. (2016). Management of acute scrotum in children: a 25year single center experience on 558 pediatric patients. Can J Urol, 23(6), 8594-601.

13. Howe, A. S., Vasudevan, V., Kongnyuy, M., Rychik, K., Thomas, L. A., Matuskova, M., ... \& Palmer, L. S. (2017). Degree of twisting and duration of symptoms are prognostic factors of testis salvage during episodes of testicular torsion. Translational andrology and urology, 6(6), 1159-1166.

14. Morin, O. A., Carr, M. G., Holcombe, J. M., \& Bhattacharya, S. D. (2019). Optimal Predictor of Gonadal Viability in Testicular Torsion: Time to Treat Versus Duration of Symptoms. Journal of Surgical Research, 244, 574-578.

15. Barbosa, J. A., Tiseo, B. C., Barayan, G. A., Rosman, B. M., Torricelli, F. C. M., Passerotti, C. C., ... \& Nguyen, H. T. (2013). Development and initial validation of a scoring system to diagnose testicular torsion in children. The Journal of urology, 189(5), 1859-1864.

16. Annette, S., Ronald, R., \& William, H. (2020). Testicular Torsion: Direction, Degree, Duration and Disinformation. [Internet]. 2003 [cited 17 June 2020]. Available from: https://pubmed.ncbi.nlm.nih.gov/12544339/

17. Jefferson, R. H., Perez, L. M., \& Joseph, D. B. (1997). Critical analysis of the clinical presentation of acute scrotum: a 9-year experience at a single institution. The Journal of urology, 158(3), 1198-1200.

18. von Zastrow, C., \& Sotelino, J. A. (2005). Wiederauftretende Hodentorsionen: Kann ein pexierter Hoden torquieren?. Der Urologe, 44(11), 1337-1340.

19. Frohlich, L. C., Paydar-Darian, N., Cilento Jr, B. G., \& Lee, L. K. (2017). Prospective validation of clinical score for males presenting with an acute scrotum. Academic Emergency Medicine, 24(12), 1474-1482.

20. Sheth, K. R., Keays, M., Grimsby, G. M., Granberg, C. F., Menon, V. S., DaJusta, D. G., ... \& Baker, L. A. (2016). Diagnosing testicular torsion before urological consultation and imaging: validation of the TWIST score. The Journal of urology, 195(6), 1870-1876.

21. Boettcher, M., Bergholz, R., Krebs, T. F., Wenke, K., \& Aronson, D. C. (2012). Clinical predictors of testicular torsion in children. Urology, 79(3), 670-674.

22. Beni-Israel, T., Goldman, M., Chaim, S. B., \& Kozer, E. (2010). Clinical predictors for testicular torsion as seen in the pediatric ED. The American journal of emergency medicine, 28(7), 786-789.

23. Soccorso, G., Ninan, G. K., Rajimwale, A., \& Nour, S. (2010). Acute scrotum: is scrotal exploration the best management?. European journal of pediatric surgery, 20(05), 312-315.

24. Bandarkar, A. N., \& Blask, A. R. (2018). Testicular torsion with preserved flow: key sonographic features and value-added approach to diagnosis. Pediatric radiology, 48(5), 735-744.

25. Xu, Y. F., Jiang, H. Y., Hu, H. Y., Wang, H. R., Geng, T. X., Pan, H. R., \& Li, X. X. (2016). Highfrequency ultrasonography for diagnosis and differential diagnosis of acute scrotum in children. Zhonghua nan ke xue= National Journal of Andrology, 22(11), 996-1000.

26. Ring, N., \& Staatz, G. (2017). Bildgebende Diagnostik beim akuten Skrotum. Aktuelle Urologie, 48(05), 443-451.

27. Ring, N., \& Staatz, G. (2017). Bildgebende Diagnostik beim akuten Skrotum. Aktuelle Urologie, 48(05), 443-451.

28. Middleton, W. D., Middleton, M. A., Dierks, M., Keetch, D., \& Dierks, S. (1997). Sonographic prediction of viability in testicular torsion: preliminary observations. Journal of ultrasound in medicine, 16(1), 23-27.

29. Cokkinos, D. D., Antypa, E., Tserotas, P., Kratimenou, E., Kyratzi, E., Deligiannis, I., ... \& Piperopoulos, P. N. (2011). Emergency ultrasound of the scrotum: a review of the commonest pathologic conditions. Current problems in diagnostic radiology, 40(1), 1-14.

30. Yagil, Y., Naroditsky, I., Milhem, J., Leiba, R., Leiderman, M., Badaan, S., \& Gaitini, D. (2010). Role of Doppler ultrasonography in the triage of acute scrotum in the emergency department. Journal of Ultrasound in Medicine, 29(1), 11-21.

31. Badea, R., Lucan, C., Suciu, M., Vasile, T., \& Gersak, M. (2016). Contrast enhanced harmonic ultrasonography for the evaluation of acute scrotal pathology. A pictorial essay. Medical ultrasonography, 18(1), 110-115.

32. Waldert, M., Klatte, T., Schmidbauer, J., Remzi, M., Lackner, J., \& Marberger, M. (2010). Color 
Doppler sonography reliably identifies testicular torsion in boys. Urology, 75(5), 1170-1174.

33. Thomas, S. Z., Diaz, V. I., Rosario, J., Kanyadan, V., \& Ganti, L. (2019). Emergency Department Approach to Testicular Torsion: Two Illustrative Cases. Cureus, 11(10).

34. Manohar, C. S., Gupta, A., Keshavamurthy, R., Shivalingaiah, M., Sharanbasappa, B. R., \& Singh, V. K. (2018). Evaluation of Testicular Workup for Ischemia and Suspected Torsion score in patients presenting with acute scrotum. Urology annals, 10(1), 20.

35. Vasdev, N., Chadwick, D., \& Thomas, D. (2012). The acute pediatric scrotum: presentation, differential diagnosis and management. Current urology, 6(2), 57-61.

36. Sharp, V. J., Kieran, K., \& Arlen, A. M. (2013). Testicular torsion: diagnosis, evaluation, and management. American family physician, 88(12), 835-840.

Cite This Article: Šečić T \& Karavdić K (2021). Predictor Factors Influencing the Final Outcome and Treatment of Pediatric Patients with Acute Scrotum - Study For a Period of 10 Years. East African Scholars J Med Surg, 3(3), 47-58. 